The " limits of safety," it may respectfully be urged, fall within the judgment of the prescriber, not within that of dispenser; and over the judgment of the prescriber most certainly the Pharmacopoia has neither warrant nor control. If, as may readily be argued, the publication of " official" doses in the Pharmacopoia promotes the public safety by enabling the dispenser to detect any accidental lapse on the part of the physician, by all means let such doses duly exist and appear. But they must not be translated as exercising any "authority" over the freedom of the practitioner. Alike in the interests of the individual patient and of the extension of exact therapeutic knowledge, there must be preserved for the physician a "liberty of prescribing"- - a liberty to use, in reference both to quantity and quality. whatever he deems likely to promote the welfare of his patient.

The one risk, such as it is, of the new proposal is that by increasing the pharmacopoeial apparatus dealing with dosage an undue importance may be attached to this part of the official volume. In short, it is within the possibilities that a definition of the "limits of safety" in dispensing may come to mean to some the "limits of safety" in prescribing. So long as adequate means are taken to avoid this result, and so, long as the pharmacopoeial doses are presented merely as doses which the pharmacist should not exceed without the special direction and authority of the physician, the profession need not much concern itself abont the proposed new departure. It matters little whether the official doses are retained in their present form or whether they are modified or extended in the direction suggested in your annotation. What is of importance, however, is to be quite clear that such doses, whatever their form, have no controlling authority over the freedom and discretion of the prescriber. The "limits of safety" in the administration of any remedy in each individual case must be judged by the practitioner in charge of the patient, and on his own responsibility; they cannot be authorised or defined either by a national or any other form of pharmacopoia.

Harley-street, W. I am, Sir, yours faithfully, C. O. HaWTHORNE.

\section{GASTRIC ULCER.}

To the Editor of THE LANCET.

SrR,-In your issue of August 20th you report Mr. E. Deanesly of Wolverhampton as having said, re excision of gastric ulcer :- "It was now known that unless there was distinct pyloric obstruction food did not pass through the new opening, and even after the operation had been done an ulcer might perforate or a new peptic ulcer might form. There was great liability to recurrence both of the pain and other symptoms. Excision should be the operation of choice in all centrally situated ulcers not involving the pylorus or the duodenum." You make no note of this statement having been questioned. Was this really the feeling of the meeting on this important point?

May I quote one case as positive evidence in the other direction in the hope that other surgeons may give us their opinion of the utility of a simple gastro jejunostomy for a chronic gastric ulcer not situated near the pylorus and not causing pyloric obstruction.

The patient, aged 23, asylum nurse, was sent to me last year to be operated on for a chronic gastric ulcer. 'The history was typical and extended over four years. She had had several attacks of hæmatemesis and had been unable to take solids for four years. Rest in bed on sparing fluid diet gave but slioht relief from the pain.

June 20th, 1909: At the operation the condition found was a large chronic ulcer in the cardiac portion of the stomach, near the lesser curvature. The pylorus was normal. A large posterior vertical junction was made.

Sept. 7th, 1909: The patient has had no pain or sickness since the operation and returned to full duty as an asplum nurse.

April 12th, 1910 : The patient has been working constantly, has put on weight, and has had no return of symptoms. On this date she was examined by the fluorescent screen, standing up, whilst slowly swallowing one ounce of bism. carb. mixed with bread and milk. The mixture could be seen passing from the stomach into the jejunum well to the left of the middle line. Meanwhile, the pyloric portion of the stomach gradually filled with the mixture, but none passed through the pylorus, a well-defined convex margin with convexity towards the patient's right hand delimiting the pyloric portion of the stomach. Immediately after the screen examination a plate was taken, and the print clearly shows the condition described above.

July, 1910: The patient continues in normal health.

Bolton has shown by experiments on rabbits that the actual necrosis and ulceration of the stomach are produced by the gastric juice acting upon a cell which is functionally damaged, and that the hyperacidity of the gastric juice increases the tendency to such ulceration, whilst the introduction of a weak alkaline solution into the stomach of a control animal prevents necrosis and ulceration of the gastric mucous membrane of control animal.

Is it not, therefore, possible that the factor determining the cure of a gastric ulcer after a gastro-jejunostomy is the fact that a large graft of jejunal mucous membrane secreting an alkaline fluid has become an integral part of the stomach wall, and that the success of the operation depends not only on making a vertical junction for mechanical reasons but on making a large junction both for mechanical and physiological reasons, and that whether the ulcer be excised or not matters little? I am, Sir, yours faithfully,

Hastings, August 25th, 1910. DAVID LiGAT.

\section{CARDIAC STRAIN.}

To the Eaitor of THE LANCET.

SIR,-Amongst varieties of strain Sir Lauder Brunton, in his recent lecture published in THE LANCET, com ments upon the effect of excessive exercise upon the heart, and lends the weight of his valuable opinion to those who consider that the heart may suffer injury. Since the days when I was a medical student I have to some degree been interested in this subject, and although the facts gleaned have been few the impressions based upon them may not be without interest. The effects of exertion upon the heart have to be considered under the headings of immediate and remote effects. Occasionally, no doubt, the power of will is greater than the physical powers of the body to carry out the purposes of the will, and alarming symptoms of distress, possibly even death, may result. Yet when the alarming symptoms stop short of death the probability is that in a few days the heart and vaso-motor system will be as capable as ever of adapting themselves to strenuous activities. Tried severely again and again they may present signs of weakness, but even after having given evidence of such weakness it seems to be doubtful whether if wisely treated they are permanently injured.

Sir Thomas Clifford Allbutt has expressed the opinion that the presence of an early stage of an infections disease, or possibly only of a feverish cold, may predispose to the immediate harmful effects upon the heart of exertion. I once met with an interesting example of this. A school girl, aged 14 years, rode upon a bicycle for 16 miles against a strong head wind. The following day the rash of measles appeared. Loud systolic murmurs were then audible over the heart, both at the apex and the base, which disappeared during convalescence. The bicycle ride during the earlier stage of the attack of measles had obviously produced dilatation of the heart and the appearance of murmurs. It may be remarked in passing that the appearance of murmurs appears to me to be a far better test of dilatation of the heart in children than increase of præcordial duIness. It is interesting to note that the girl was able to ride 16 miles against the wind the day before the rash appeared. If a girl in an early stage of measles will indulge in active exercise, many a boy, no doubt, will not allow slight feelings of illness to interfere with his desire to take part in competitions involving physical strain, and before we blame physical strain alone such an important factor as concomitant illness requires to be eliminated.

In the healthy heart, however, apparently repeated strain may produce symptoms of disordered function. Perhaps I may be allowed to give solne personal experience. In the days of my boyhood and youth my heart used frequently to be subjected to considerable strain without any definite training. For example, I once won a three mile race without haring run a mile for about two years. After the age of $30 \mathrm{I}$ engaged somewhat energetically in cycling; riding hill which were considered to be unridable being a weakness in which I indulged. At the end of about two years some cardiac pain was experienced associated with occasional intermission of the pulse. These symptoms were taken as an indication for the more judicious use of the bicycle, and after about 
two years they entirely disappeared. It is to be feared that foolish acts are still sometimes committed without, however, ill-effects being noticed. Twice wilhin the past five years I have run three miles. This is not an act to be commended for anyone in middle-age, but it is mentioned to show that in spite of the presence at one time of cardiac pain and intermission of the pulse my heart retains a power for continued exertion.

One sometimes hears of the hypertrophied heart of athletes. That it often exists seems to me to require projf. Hypertrophy of the heart is, it is needless to say, occasionally met with in the post-mortem room, which is apparently the result of over-exertion, but possibly it is not excessive work merely but excessive work in the presence of heat that may lead to hypertrophy of the beart. In other woras, it may be that the hypertrophy of the heart in a gasstoker or in a blacksmith is probably largely toxic. Owing to most of the fluid drunk being passed off by the skin rather than by the kidneys toxic products of metabolism are retained in the body and poison the heart. However true this explanation of the hypertrophy may be, it is very difficult to find any kind of arduous occupation which requires to be carried on in the open air that occasions hypertrophy of the heart. If we allow for the normal variations in the size of the heart and of the situation of the impulse in different individuals it is doubtful whether we should find the heart of the athlete to be often hypertrophied.

This letter, one regrets, is discursive. Briefly it is intended to urge that although few, if any, will deny that excessive exercise may temporarily derange the heart it is very doubtful whether exercise a!one, apart from some contributing factor, causes permanent injury.

I am, Sir, yours faithfully,

August 19th, 1910 THEODORE FISHER.

\section{BLIND MASSEURS FOR BERI-BERI PATIENTS.}

To the Editur of THE LANCET.

SIR, - While I understand the letter published in THE LANCET of Augast 20 th with the above title is a "disclaimer," yet on reading it am I to understand that as well as disclaiming Dr Cantlie belittles the idea of massage in beriberi? If so, I can assure him that I have seen the best of results from massage as performed by a real $\$$ wedish masseur, but he was not blind. From what I do remember of the treatment I would suggest to those who have not tried it to give it a trial.

August 25th, 1910.

I am, Sir, yours faithfully, T. L. AshForTh, L.R.C.P. Edin.

\section{"SUBJECTS OF SURGTCAL INTEREST."}

\section{To the Editor of THE LANOET.}

SrR,-My attention has been called to a letter in your issue of August 20th on the above subject by Dr. Wm. Bennett of Manchester. In the course of his remarks he states that "general practitioners will thank $\mathrm{Mr}$. Waterhouse for simplifying the disinfecting of operation surfaces." So far as I am aware, I was the first surgeon to advocate the use of tincture of iodine for this purpose. If Dr. Bennett will refer to the Britzsh Medicat Journal of August 4th, 1909, he will find my original paper, which was published several months before Mr. Waterhouse's.

$$
\text { I am, Sir, yours faithfully, }
$$

\section{J. LIONEL STRETToN,}

Senior Surgem to the Kidderminster Infirmary

Kidderminster, August 29th, 1910

$$
\text { and Chilaren's IIospital. }
$$

\section{DR. C. E. HARRIS FUND.}

To the Elitor of THE LANCET.

Sir, - We beg to forward you the audited accounts of the above fund. After deducting certain necessary expenses on behalf of Mrs. Harris and her children, during the past year, we have invested the balance - viz., $£ 1735 s$-in the purchase of an arnuity of $£ 20$ for a period of ten years, to be paid to the widow by quarterly instalments. Provision for the six children has been made as follows: (1) The two eldest boys have been admitted to the Fortescue $H$ ruse School, Twickenham (National Refuges); (2) the third boy was successful at his first application for admission to the Royal
Asylum of St. Anne's Society, Redhill ; (3) the two eldest girls have been admitted to the Girls' Home, Royston (National Refuges); and (4) the youngest girl has been admitted to the Kingsdown Orphanage, Hornsey, for which a friend is paying $£ 33 s$. annually.

We wish to express our most sincere thanks to all donors for their ready response to our appeal, and to all those who have so generously helped us in many other ways; to the Editors of THE LANCET and the Medioal Offoer for giving publicity to our appeal, and to Mr. E. W. Drew for his kindness in auditing the accounts.

\section{We are, Sir, yours faithfully,}

\section{N. H. TURNER, > Honorary Secretaries} Carl Prausntiz, $\}$ and Treasurers.

35, Higbbury-grove, London, N., August 15th, 1910.

** The donations amounted, together with a small sum as interest and as commission from the Commercial Union Assurance Company, from whom the annuity was purchased, to $£ 2054 s .1 d .-\mathrm{ED}$. L.

\section{THE SUPPRESSION OF QUACKERY.}

\section{To the Editor of THE LANCET.}

SIR,-A sense of humour is an advantage always and everywhere. Mr. Pickin possesses it evidently. I should be sorry to think myself devoid of it, but, as I have no doubt he will agree, it ought not to blind us to the serious facts of the quackery question. Credulity among great sections of the ignorant masses and "educated" classes is as gross at the present day as it was in the days when belief in witchcraft was universal, but this does not lessen the obligation of Government to protect weak and simple citizens against the army of cynical rascaldom that now, thanks to the weakness of the law, is able with impunity to exploit them. There is much that is funny and farcical to be found in quackery, as, for example, in the practices of "beauty doctors" and obesity curers. In these directions it is often simply fraudulent, but in most other directions, even where it appears harmless, it is not only fraudulent, it is cruel and deadly. If $\mathrm{Mr}$. Pickin is a practitioner, he may easily ascertain these facts for himself by systematic observation and diplomatic inquiry among his patients. The first case that attracted my attention to the subject many years ago was that of a woman who had allowed a cancer of her breast to go on to a hopeless phase whilst relying upon a heal-all ointment composed of coloured lard. It is easy to illustrate this subject by reference to every class of quack medicines. The victims are perhaps easiest to discover among hospital patients. Teething and baby-quieting medicines form the direct causes of death in a vast number of cases. They turn away attention from the real calnse of the baby's outcries, in most cases intestinal pain, and keep it quiet on the way to death or survival as a degenerate wastrel. The mischief arising from quack nostrums of all sorts is well exemplified by the class of indigestion cures. Indigestion is merely a symptom. not a distinct disease. It of ten indicates a simple functional disturbance, but even then the proper treatment is not continuous dosing with aloes, or other cheap purgative, which is invariably the only potentingredient of secret remedies for this complaint. On the other hand, "indigestion " may be a sign of organic or malignant disease anywhere within or in the neighbourhood of the alimentary canal. Cases of the more serious kinds are always to be found in hospitals, and inquiry usually discloses the fact that they have been dosing themselves with quack medicines until their malady having assumed a serious or mortal phase they have been compelled to seek relief in the wards. In late years I have given up systematically inquiring for such cases, but some time ago I casually came across a series whilst acting as visiting member of the committee of our small local hospital. These were women suffering from ulcer of the stomach. Nearly all of them had been taking for prolonged periods one or other of the most advertised indigestion cures, the sole active ingredient of which is aloes. One case ended fatally; it might perhaps have been saved by early diagnosis and treatment. Between $£ 3,000000$ and $£ 4,000,000$ are now being spent annually upon quack remedies and bogus apparatus, and if it be admitted that the majority of dupes of these forms of coarse quackery receive no permanent injury it will still be evident that the large percentage of victims that are badly or fatally hurt represents a terrible mass of preventable human suffering and misery. The traffic in secret 